\title{
Antifungal and Insecticidal properties of the Phytoconstituents of Drimys winteri (Winteraceae) growing in Chiloe Island
}

\section{(Chile)}

\author{
Muñoz $\mathbf{O}^{1^{*}}$, Gutierrez $\mathbf{M}^{2}$, Gonzalez $\mathbf{R}^{3}$, Hammann $\mathrm{S}^{4}$ and Vetter $\mathbf{W}^{4}$
}

${ }^{1}$ Departamento de Química, Facultad de Ciencias, Universidad de Chile, Casilla 653, Santiago, Chile

${ }^{2}$ Laboratorio de Síntesis Orgánica, Instituto de Quimica de Recursos Naturales, Universidad de Talca, Talca, Chile

${ }^{3}$ Facultad de Ciencias Agronomicas, Universidad de Chile

${ }^{4}$ University of Hohenheim, Institute of Food Chemistry (170b), Garbenstr, 28, D-70593 Stuttgart, Germany

\begin{abstract}
Seven drimane-type sesquiterpenes: polygodial, drimenol, drimendiol, drimenin, isodrimininol, isodrimenin and proximadiol (cryptomeridiol); three lignans: sesamin, cubebin and its epimer eudesmin, and one sterol: ( $\beta$-sitosterol) were isolated from Drimys winteri (Winteraceae) from Chiloe Island, Chile. Eudesmin and its phytosterols were isolated from the plant for the first time, and sesamin was found to be the major product in the plant's bark by a significant margin. Furthermore, qualitative and quantitative differences were detected between some products. Structures were established using 1D and 2D NMR (COSY, HSQC, and HMBC) spectra, HRESIMS and comparison with published data. Some isolated compounds were tested against the phytopathogenic fungi Botritys cinerea, Dothiorella sp., Penicillium sp. and Cladosporium cladosporoides; additionally, a study was carried out to determine the contact toxic action of leaf and stem bark extracts upon phloematic insect pests from the Pseudococcus viburni (Signoret) (Hemiptera: Pseudococcidae) mealy bug complex.
\end{abstract}

Keywords: Drimys winteri; Lignans; Sterols; Sesquiterpenoids; Antifungal activity; Insecticidal properties

\section{Introduction}

Drimys winteri J. R and G. Forster var. chilensis (DC.) A. Gray is a tree native to Central and Southern Chile, which grows in continental Chile from Coquimbo to Aysén, including Chiloé Island. It is abundant in wet swampy localities from sea level to an altitude of $1700 \mathrm{~m}$ [1]. In continental Chile, Winteraceous plants are represented by two species of Drimys: D. winteri J. R. Forster and G. Forster and D. andina Reiche [2]. D. winteri is a tree whereas D. andina is a shrub [3]. Marticorena and Quezada also distinguish the chilensis (DC.) A. Gray variety of $D$. winteri [4]. Drimys winteri is a sacred plant to the Mapuche indigenous people, who uses its aerial parts for the treatment of dermatitis, stomach pain, toothache, tumors, and other illnesses [5]. Extracts of the stem bark have long been used to treat human and bovine diseases [6]. In the past, the stem bark of D. winteri was exported to Europe as an antiscorbutic medicine [1,5]. The tree is also used for commercial purposes, in wood production, crafts, manufacturing and the pulp industry due to the high quality of its fibers. Its architectural characteristics and natural resistance to insects and microorganisms are advantageous for playgrounds in parks and gardens in a wide range of weather conditions. The wood of this species is highly valued and used to manufacture furniture and musical instruments as well as to protect crops [7]. Furthermore, extracts of aerial parts of $D$. winteri have industrial applications in products such as cosmetics, phytonutrients and pest repellent agents [7-9]. Previous reports on the chemical composition of continental $D$. winteri revealed the presence of tannins, flavonoids and essential oils containing sesquiterpene lactones [5]. The drimane-type sesquiterpenoids possess a wide variety of biological activities, including antimicrobial, pungency, antibacterial, antifungal, antifeedant, cytotoxic, molluscicidal, piscicidal, growth regulation and phytotoxic properties [9]. The pungency of several drimanes and their irritant properties on the skin (allergies) has also attracted attention [610]. To the best of our knowledge, as of the present, fourteen drimanetype sesquiterpenoids have been isolated from continental $D$. winteri and probably also from $D$. andina $[5,6]$, as well as one aromadendrane derivative [11] and one drimane-type sesquiterpene trimer [12]. The sesquiterpenes reported from the bark and leaves collected in Brazil [13] were not considered because D. winteri is not present in Brazil [3]. The main characteristics and properties of this tree have been attributed to the presence of certain sesquiterpenoids. The reactivity of the unsaturated dialdehyde functionality towards biological nucleophiles is considered responsible for the antifeedant activity of those compounds (polygodial and epipolygodial) $[14,15]$. The chemical composition of the essential oils obtained by hydrodistillation of the stem bark and leaves of continental Chile (Santiago) D. winteri was also studied using GC and GC/MS for which results have been published [16]. The essential oils from the stem bark and leaves of $D$. winteri from Chiloé Island and continental Chile (Santiago) were studied revealing certain differences in their chemical composition. Sesquiterpene hydrocarbons constituted the main chemical groups in the stem bark oils (in which $\alpha$-santalene, trans - $\beta$ - bergamotene curcumenes are the major components), whereas monoterpenes (in which $(\alpha)$ - pinene, $\beta$-pinene, and linalool are the main components) constituted the main chemical groups in the leaves of Island plants. Sesquiterpenes (germacrene) and phenylpropanoids are most abundant in the leaves of continental plants [16]. The aim of the present study was to compare the chemical profile of insular $D$. winteri from Chiloé Island (growing and flourishing in climate conditions of high humidity, abundant water and very scarce volcanic soil) that differ greatly from those where the continental population is found. We also separately investigated the components present in the bark and leaves and evaluated their

*Corresponding author: Orlando Muñoz, Professor, Universidad de Chile, Chemistry Las Palmeras 3425 Ñuñoa Santiago, Santiago 7800003, Chile, Tel: 56-2-92343886 Fax: 56-2-22713888; E-mail: omunoz@uchile.cl

Received May 28, 2015; Accepted July 07, 2015; Published July 15, 2015

Citation: Muñoz O, Gutierrez M, Gonzalez R, Hammann S, Vetter W (2015)Antifungal and Insecticidal properties of the Phytoconstituents of Drimys winteri (Winteraceae) growing in Chiloe Island (Chile). Nat Prod Chem Res 3: 182. doi:10.4172/23296836.1000182

Copyright: $\odot 2015$ Muñoz O, et al. This is an open-access article distributed under the terms of the Creative Commons Attribution License, which permits unrestricted use, distribution, and reproduction in any medium, provided the original author and source are credited. 
insecticidal and antifungal properties for potential industrial use. The investigation also showed an unusual concentration of the sesamin lignan in bark from Chiloe canelo populations in comparison with continental populations, which would partially explain its extensive use by the local population as a treatment for certain conditions [17]; and the absence of bacteria and insect attacks on the species [18]. Until now, neither the existence of the lignan eudesmin nor its phytosterol content had been reported. This study also evaluates its possible use as a dietary supplement.

\section{Materials and Methods}

\section{General}

Column chromatography (CC) was carried out using silica gel 60G (Merck 7734, Germany). Thin layer chromatography (TLC) took place on silica gel GF254 (Merck 5554) with i) hexane-ethyl acetate $8: 2$ and ii) hexane-acetone $8: 2$. Spots were detected by UV light or with a Liebermann-Burchard reagent and heated to $110^{\circ} \mathrm{C}$ for $1 \mathrm{~min}$. Prep. TLC was performed on 2-mm thick silica gel $\mathrm{F}_{254}$ plates (Merck 7731) and Chromatotron (Harrison-research 7924 T) 1 or 2 mm thick discs, using silica gel 60 PF 254 (Merck 7749). Flash chromatography took place on silica gel $60 \mathrm{H}$ (Merck 7739) with a hexane-ethyl acetate gradient of $0-100 \%$ EtOAc. Mps are uncorrected. Optical rotations were measured with a Perkin Elmer $241 \mathrm{MC}$ polarimeter. ${ }^{1} \mathrm{HNMR}$ spectra at $500 \mathrm{MHz}$ were recorded in $\mathrm{CDCl}_{3}$ on a Bruker-DRX $500 \mathrm{MHz}$ ${ }^{1} \mathrm{H}$ Larmor frequency equipped with a $5-\mathrm{mm}$ probe. ${ }^{1} \mathrm{H},{ }^{13} \mathrm{C}$ and $2 \mathrm{D}$ (COSY, HMQC, HMBC) experiments were performed using standard Bruker pulse sequences. Capillary NMR spectra were recorded on a Varian Unity Inova $500 \mathrm{MHz}$ spectrometer (Palo Alto, CA) equipped with a Protasis/MRM capNMR probe (Savoy, $\mathrm{Il}$ ) in $\mathrm{CDCl}_{3}$ and $\mathrm{MD}_{3} \mathrm{OD}$ by direct injection of $7 \mu \mathrm{L}$ samples. Proton assignment was determined using ${ }^{1} \mathrm{H}$ and COSY spectra while the carbon data was taken from HSQC and HMBC experiments.

\section{Plant material}

Drimys winteri var. chilensis was collected in February, June, September and December 2008 and 2009 on Chiloé Island, 30 km NW of Castro and $17 \mathrm{Km} \mathrm{SE}$ of Chonchi Beach (Chile), within the same population. Voucher specimens are held at the Faculty of Sciences, Universidad de Talca (herbarium numbers 107-08). The plants were identified by Dr. José San Martin (Universidad de Talca, Instituto de Biología Vegetal y Biotecnología).

\section{Extraction and isolation}

Leaves were dried at room temperature for 3 weeks. Stem bark was dried in a forced-air oven at $40^{\circ} \mathrm{C}$ for $48 \mathrm{~h}$.

1. Dried and powdered D. winteri stem bark (700 g) was extracted using $n$-hexane $(3 \times 2.0 \mathrm{~L})$ at room temperature for 72 hours. After filtration, the residue was placed in a Soxhlet apparatus and extracted again using $n$-hexane for 24 hours. The solutions were combined and evaporated under reduced pressure $(210 \mathrm{mbar})$ at $25-30^{\circ} \mathrm{C}$ to produce a yellowish oily residue $(35.0 \mathrm{~g})$. The crude extract was first subjected to flash CC (silica gel, 230-400 mesh, $650 \mathrm{~g}$ ) and fractionated by gradient elution ( $100 \% n$-hexane to $100 \%$ EtOAc), and individual fractions were then further purified by two CC on silica gel. Elution with $n$-hexaneethyl acetate (98:2-90:10) yielded $2.84 \mathrm{~g}$ of a yellow mixture consisting of four compounds. Further separation using the Chromatotron yielded $1.050 \mathrm{~g}$ of polygodial $1 ; 0.015 \mathrm{~g}$ of drimenol $2 ; 0.052 \mathrm{~g}$ of drimenin 4 and $0.010 \mathrm{~g}$ of proximadiol. The fractions eluted with $n$-hexane - EtOAc (4:2) provided a mixture of $0.52 \mathrm{~g}$ of drimendiol 3, $0.15 \mathrm{~g}$ of Isodrimenin (b) and another compound identified as sesamin c (0.95 g) (b).

2. Powdered leaves ( $350 \mathrm{~g})$ were Soxhlet-extracted using the same procedure as described for stem bark and produced $25.9 \mathrm{~g}$ of yellow residue. Part of this (17.5 g) was mixed with basic aluminum oxide 90 (Merck) and subjected to chromatographic separation using an $n$-hexane-ethyl acetate solvent mixture. Elution with $n$-hexane-ethyl acetate (9:1) yielded $0.65 \mathrm{~g}$ of a yellow residue consisting of a mixture of four compounds. Further separation using the Chromatotron (film thickness $2 \mathrm{~mm}$ ) and elution with $n$-hexane-ethyl acetate (8:2) produced three main compounds which were further purified by CC (silica gel 230-400 mesh, $600 \mathrm{~g}$ ) and fractionated by $n$-hexane-ethyl acetate (9:1 to $8: 2)$ gradient elution yielding cubebin $(0.12 \mathrm{~g})$, its epimer (epi-cubebin $(0.061 \mathrm{~g})$ and eudesmin $(0.041 \mathrm{~g})$; Sesamin was also isolated.

Polygodial (Figure 1) (Scheme a): [a] D and spectroscopic data (NMR, MS) were identical to data previously reported on this compound [6].

Drimenol (Figure 2) (Scheme a): The MS, ${ }^{1} \mathrm{HNMR}$ and ${ }^{13} \mathrm{CNMR}$ data on this compound correlated well with that reported elsewhere $[12,19,20]$.

Drimendiol (Figure 3) (Scheme a): The ${ }^{1} \mathrm{HNMR}$ and ${ }^{13} \mathrm{CNMR}$ spectral data on this compound correlated well with that reported elsewhere [6].

Drimenin: The MS, ${ }^{1} \mathrm{HNMR}$ and ${ }^{13} \mathrm{CNMR}$ spectral data on this compound correlated well with reported data $[20,21]$.

Isodrimeninol: Already identified in D. winteri [6].

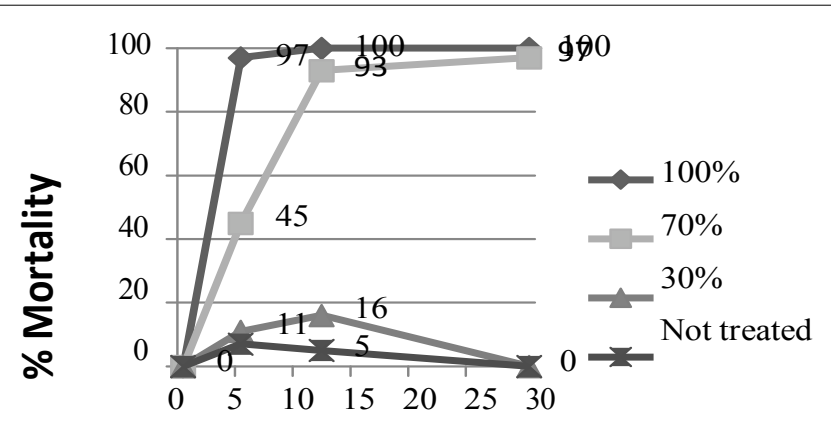

Days after treatment

Figure 1: Mortality with Treatment $A$ (stem-bark) at different dilution rates.

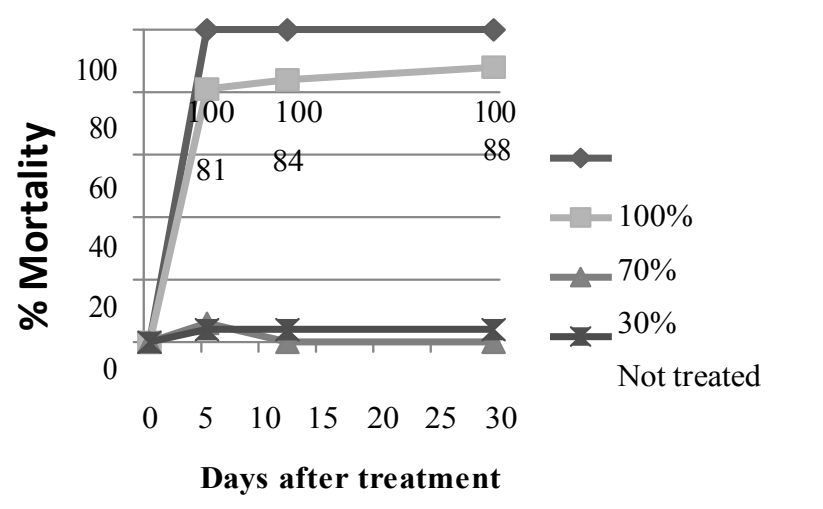

Figure 2: Mortality with the Treatment B (leaves) at different dilution rates. 


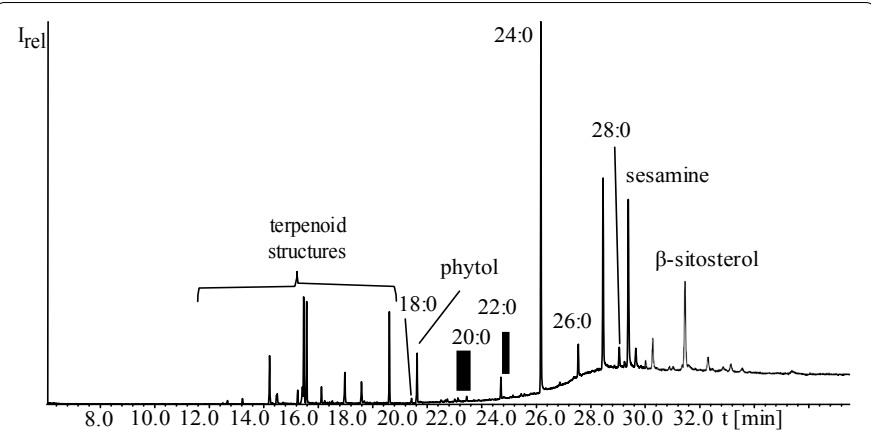

Figure 3: GC/MS chromatogram of unsaponifiable matter from Drymis winteri. Compounds labeled 18:0 -26:0 are alcohols.

Isodrimenin: Previously isolated from D. winteri [22]. ${ }^{1} \mathrm{HMNR}$ and ${ }^{13} \mathrm{C}$ NMR was also reported [23].

Proximadiol (syn. cryptomeridiol): Already isolated from $D$. winteri. The ${ }^{1} \mathrm{HNMR}$ and ${ }^{13} \mathrm{C}$ spectral data on this compound correlated well with reported data $[24,25]$.

(+) -Sesamin (c): Already identified in D. winteri by Cortes [26]. Its ${ }^{1} \mathrm{HNMR}$ and ${ }^{13} \mathrm{C}$ NMR spectra have already been reported [27]. Cubebin (mixture of 2 epimers), this compound was already isolated from D. winteri by Brown [11]. The ${ }^{1} \mathrm{HNMR}$ and ${ }^{13} \mathrm{CNMR}$ spectral data on this compound correlated well with that reported elsewhere [28]. Eudesmin is reported in D. winteri for the first time. The ${ }^{1} \mathrm{HNMR}$ and ${ }^{13} \mathrm{CNMR}$ spectral data on this compound correlated well with that reported elsewhere [29].

\section{Antifungal activity}

Antifungal activity against Botrytis cinerea Pers., Dothiorella sp., Penicillium sp. and Cladosporium cladosporoides was determined in triplicate experiments by microdilution [30-32] and the results are presented as the minimum inhibitory concentration (MIC). The spores were cultured on Saboureaud medium at $25^{\circ} \mathrm{C}$ for 7 days. The compounds were assessed in the $600-18.75 \mu \mathrm{g} / \mathrm{ml}$ dilution interval, and standard antifungal compounds were assessed in the of $250-3.9 \mu \mathrm{g} / \mathrm{ml}$ range. Spores were obtained from well-grown and sporulating fungal cultures maintained in potato-glucose agar medium by suspension in sterile distilled water, filtration on glass wool and centrifugation. The spores were counted in a Neubauer chamber and diluted with sterile distilled water to a final concentration of $10^{4}-10^{5} \mathrm{spores} / \mathrm{ml}$. The assay was carried out in 96-well microtiter plates. $100 \mu \mathrm{l}$ of the spore suspension was incubated with $100 \mu \mathrm{l}$ of the compound sample suspended in Saboureaud medium. The final volume of the mixture was $200 \mu \mathrm{l}$. A spore germination control and a Saboureaud medium control were included in all of the experiments as well as the standard fungicides iprodione [3-(3, 5-dichlorophenyl)- $N$-isopropil-2, 4-dioxoimidazolidine-1-carboxamide] (Rukon, Aventis Crop Science, France) and myclobutanil [R-butyl-R-(4-chlorophenyl)-1H-1, 2, 4-triazol-1-propanonitrile] (Systhane, Dow AgroSciences, Chile). The MIC is defined as the lowest concentration of the compound without visible spore germination after the incubation time ( 7 days). The major compounds were evaluated and a mixture of compounds was evaluated to examine the synergic effect.

\section{Insecticidal properties}

A preliminary trial was conducted to determine the contact toxic action of leaf and stem bark Drymis winteri extracts on phloematic insect pests from the mealy bug complex (Hemiptera: Pseudococcidae).
These primary pests are small, soft-bodied plant feeding insects, from 2 to $5 \mathrm{~mm}$ in length, able to be laboratory-reared on potato tube sprouts. Small target colonies of about 25 immature forms were selected from each potato tuber to be sprayed with the selected treatments after their establishment on the host plant. Mother insect colonies of 25 individuals each were kept on separate potatoes at a laboratory temperature ranging from 15 to $28^{\circ} \mathrm{C}$ under fairly dark conditions to avoid migration. On day 20 , spray treatments were applied using an electric dispenser and evaluated for mortality at 5, 12 and 20 days thereafter. At the time of spraying, mealy bugs had been developed from last (third) nymphal stage to young adult females. The solutions extracted from stem bark and leaves were individually diluted in $3 \mathrm{ml}$ of distilled water and microsprayed in droplets of about 50-60 microns in diameter on the colonies settled on each tuber. Treatments included the following concentrations:

a) A stem bark concentration of $1.95 \%$ solution in ethanol (solution A), and further diluted in ethanol at 70\% (solution B) and $30 \%$ (solution C);

b) A leaf extracts at the same dilutions as above, $1.75 \%$ (solution D), $70 \%(\mathrm{E})$ and $30 \%(\mathrm{~F})$.

Three $\mathrm{ml}$ of each of the 6 dilutions in distilled water were used to spray each replication. In addition, untreated control colonies were only sprayed with $3 \mathrm{ml}$ of distilled water. Treatments included 6 replicates, as follows:

Treatments A (Stem bark extracts):

$1.1 \mathrm{ml}$ of solution $\mathrm{A}$ in $3 \mathrm{ml}$ of water.

$2.1 \mathrm{ml}$ of solution B in $3 \mathrm{ml}$ of water.

3. $1 \mathrm{ml}$ of solution $\mathrm{C}$ in $3 \mathrm{ml}$ of water.

Treatments B (Leaf extracts):

$1.1 \mathrm{ml}$ of solution $\mathrm{D}$ in $3 \mathrm{ml}$ of water.

2. $1 \mathrm{ml}$ of solution $\mathrm{E}$ in $3 \mathrm{ml}$ of water.

3. $1 \mathrm{ml}$ of solution $\mathrm{F}$ in $3 \mathrm{ml}$ of water.

Mortality counts were assessed at days 5, 12 and 20 after spraying treatments. To determine full mortality, specimens were punctured slightly under a binocular microscope (Figure 1 and 2).

\section{Analysis of phytosterols chemicals}

$n$-Hexane and methanol (HPLC grade) from Th. Geyer (Renningen, Germany).

Technical grade ethanol (distilled prior to use) from BASF (Ludwigshafen, Germany). Potassium hydroxide ( $\mathrm{KOH},>85 \%)$ from Carl Roth (Karlsruhe/Germany). Pyridine (purity > 99.8\%) from Sigma-Aldrich (Steinheim, Germany) and silylating agent consisting of 99\% N, O-bis (trimethylsilyl) trifluoroacetamide (BSTFA) and $1 \%$ trimethylchlorosilane (TMCS) from Supelco (Bellefonte, PA, USA).

\section{Saponification and trimethylsilylation}

For saponification, about $50 \mathrm{mg}$ of plant material was heated in a test tube in $2 \mathrm{~mL}$ ethanolic $\mathrm{KOH}$ solution (prepared from $9 \mathrm{~mL}$ ethanol and $1 \mathrm{~mL} \mathrm{KOH} 50 \%$ in water $(w / w)$ ) for 60 minutes at $80^{\circ} \mathrm{C}$. After cooling to room temperature, $2 \mathrm{~mL} n$-hexane and $2 \mathrm{~mL}$ water was added. The tube was closed and shaken vigorously. The organic phase was transferred into a vial. An aliquot (corresponding to $\sim 0.1$ $\mathrm{mg}$ of unsaponifiable matter) was transferred to another vial and the 
solvent was stirred by means of a gentle stream of nitrogen. Pyridine $(25 \mu \mathrm{L})$ and $50 \mu \mathrm{L}$ of the silylation agent were added to the residue and the closed vial was heated for $30 \mathrm{~min}$ at $60^{\circ} \mathrm{C}$. Afterwards, the solvent was stirred by means of a gentle stream of nitrogen and the residue rediluted in $1 \mathrm{~mL} n$-hexane. This solution was used for GC/MS analysis.

\section{GC/MS conditions}

Analyses were carried out using a 6890/5973N GC/MS system (Agilent, Waldbronn, Germany) equipped with an MPS2 autosampler system (Gerstel. Mülheim/Germany). Injections $(1 \mu \mathrm{L})$ were performed in splitless mode. The temperatures of the injector, transfer line, ion source and quadrupole were set to $250^{\circ} \mathrm{C}, 280^{\circ} \mathrm{C}, 230^{\circ} \mathrm{C}$ and $150^{\circ} \mathrm{C}$, respectively. An HP-5MS UI column (30 m, $0.25 \mathrm{~mm}$ i.d., $0.25 \mu \mathrm{m}$ film thickness, Agilent, Waldbronn, Germany) was installed in the GC oven. Helium (purity 5.0) was used as carrier gas with a flow rate of $1.2 \mathrm{~mL}$ min-1. The GC oven was programmed as follows: After $1 \mathrm{~min}$ at $55^{\circ} \mathrm{C}$ the temperature was increased by $10^{\circ} \mathrm{C} / \mathrm{min}$ to $300^{\circ} \mathrm{C}$. This temperature was held for $10 \mathrm{~min}$. Data was recorded in full scan mode from $\mathrm{m} / z 50-550$ after a solvent delay of $6 \mathrm{~min}$.

\section{Results and Discussion}

In this paper, we have reported the compounds isolated from Chiloe Island Drimys winteri: six drimane-type sesquiterpenoids (a, $1-5$; b), one sesquiterpene eudesmane (cryptomeridiol), the lignans sesamin (c), cubebin as a mixture of two epimers and the non-phenolic furofuran lignin $(+)$ eudesmin. The complete ${ }^{1} \mathrm{HNMR}$ and 13CNMR spectral data on this compound correlated well with that reported elsewhere [6,19,24,28,29,33,34] (Scheme a). All compounds, except eudesmin and $\beta$-sitosterol had been previously isolated from continental $D$. winteri, yet there some qualitative and quantitative differences between them, particularly in terms of essential oils and some sesquiterpenes (Scheme b). Polygodial (a, 1) was the main sesquiterpene from the stem bark of trees growing in Chiloé Island. It was also found at lower concentration in leaves. Unlike continental tree populations; it had been previously isolated from $D$. winteri from the continental population [26]. It is well-known insect antifeedant acting on several insects $[8,14,15]$. Polygodial was the most active compound against Botrytis cinerea; mixing polygodial with drimenin or with isodrimeninol increased activity against $B$. cinerea, Dotiorella sp. and Cladosporium cladosporoides. No compound was active against Penicillium sp. The polygodial-drimenin mixture showed a major increase in the aforementioned activity. Table 1 shows the antifungal activity of the compounds and mixtures on phytopathogenic fungi, expressed in $\mu \mathrm{g} / \mathrm{mL}$. These results agree with a previous report [35], which showed polygodial to be the most potent antifungal compound, which became much more potent when combined with perillaldehyde. The synergy of polygodial and perillaldehyde against bacteria was the first example of the synergistic effect of polygodial against both Grampositive and Gram-negative bacteria [36]. In insular D. winteri stem bark, drimenol (a, 2), was found at lower concentrations than polygodial. However, it was detected in continental D. winteri [6], in addition to drimendiol, a drimane sesquiterpenoid also previously isolated by Brown [11]. Drimendiol (a, 3) was also detected in the June and September collections. The sesamin lignin was also isolated from the stem bark. This compound is highly valued as an insect repellant for protecting building materials against undesired insect infestations. Because some lignans have potent antimicrobial, antifungal, antiviral, antioxidant, insecticidal and antifeedant properties, they probably play an important role in defending plants against various biological pathogens and pests [37]. At the ecological level, they are involved in plant interactions with other organisms, mainly due to their defensive role, and in protecting plants from physical damage. Methylendioxyphenyl (piperonyl) derivatives such as cubebin, sesamin have been described as feeding inhibitors, feeding deterrents, or larval growth inhibitors [38]. Substituents such as the methoxy or methylendioxy groups enhance this activity not only in lignans but also in simple phenylpropanoids [39]. This could explain the anti-insect activity of Chiloé Drimys wineri. The high quantities of this lignan found in stem bark from insular D. winteri in comparison with those found in continental species could also explain the insecticidal properties of the insular specimen (Table 1). Sesamin has a strong allemonal biological-like activity, making it useful as a natural industrial insecticide and pest repellant. Consequently, the fungicidal and bactericidal actions of several purified extracts of insular $D$. winteri are under investigation [39] (Scheme c). A recent report on sesamin [17]

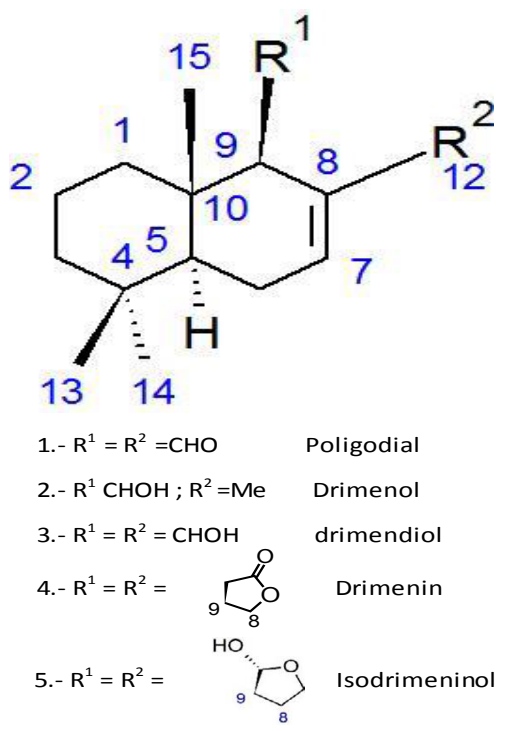

Scheme a: Chemical structures of compounds isolated from D.winteri $F$<smiles>CC1(C)CCC[C@]2(C)C3=C(CC[C@@H]12)COC3=O</smiles>

Scheme b: Chemical structure of Isodrimenin.

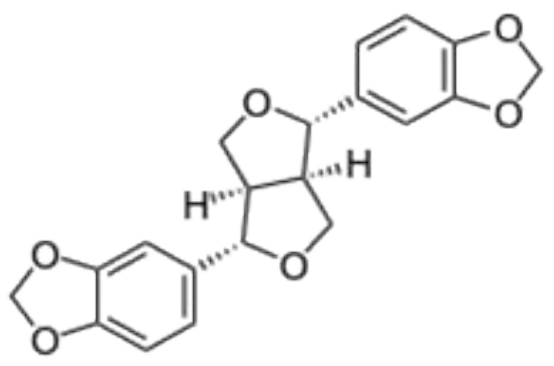

Scheme c: Sesamine chemical structures 
describes this important lignan as chondroprotective and antiinflammatory; therefore it is a new and powerful natural option for treating arthroses. Arthrosis, or osteoarthrosis, is a chronic and degenerative disease leading to deterioration and loss of hyaline articular cartilage, alterations in the subchondral bone and damage to soft tissues, including the synovial membrane. The high sesamin concentrations in Chiloé canelo bark offer a powerful natural alternative for the treatment of this condition, which is widespread in Chile. Due to their strong antifeedant, antimicrobial and pungency activity, we investigated naturally occurring sesquiterpenoid dialdehydes from the drimane series, such as polygodial and others $[3,40]$. In insular $D$. winteri, the main compounds found in stem bark and leaves are the polygodial, drimenol and drimendiol sesquiterpenoids and the sesamin, cubebin and eudesmin lignans respectively. However the main fungistatic activity is in the leaves, mainly due to the presence of sesamin, cubebin, eudesmin and polygodial, although it is also found in the stem bark, due to the presence of polygodial. These results corroborate the variability of this plant's chemical constituents. Variability in the chemical composition of continental Chile Drimys populations has already been studied, particularly for polygodial and drimenol. In dried leaves, the mean concentration is ca. $1 \%$ for polygodial and $0.011 \%$ for drimenol. This concentration depends on the population, regions, biological material studied and the time of harvest. In Chiloe Island, we found lower concentrations of drimenol in leaves, (ranging from undetectable quantities to almost $0.1 \%$ in the Southern Hemisphere winter, June to August); however bark drimenol concentrations are greater than in the leaves, whereas differences in polygodial content were not significant in comparison with continental populations. The presence of other sesquiterpenes such as drimenin (a, 4), isodremininol (a, 5), isodrimenin (b), also changes significantly in Drimys leaves and bark from Chiloe; the lowest mean value was observed in leaves; concentrations ranged from undetectable quantities to almost $0.2 \%$. The mean drimendiol concentration in summer (December - January) in Chiloe bark is $1.1 \%$, while in winter or spring it is undetectable (Table 2). Proximadiol (cryptomeridiol) shows similar concentrations to those of continental plants, although it disappears in winter. The cubebin and eudesmin lignans were also detected and isolated in Drimys winteri leaves from Chloe Island, but were not detected in bark. In leaves, the sesamin lignan was found in concentrations of almost $2.71 \%$. Cubebin has also demonstrated biological activity, for which reason the use of Aristolochia esperanzae Kuntze is indicated for treating rheumatoid arthritis. Phytochemical analysis of A. esperanzae stems reveals a mixture of cubebin [41]. Furthermore, Cubenin has significant anti-inflammatory and analgesic effects similar to those observed in non-steroidal drugs. It can this be inferred that cubenin is one of the compounds responsible for the activity already known in popular medicine [42]. Finally, some of the isolated compounds were tested against the phytopathogenic fungi Botritys cinerea, Dothiorella sp., Penicillium sp. and Cladosporium cladosporoides. Polygodial was the most active compound against Botrytis cinerea (Table 3). (Figures 1-2) show the insecticidal properties of three treatments using different Drymis winteri stem and leaf extract dilution rates against fruit tree mealy bug Pseudococcus viburni reared on potato sprouts. Average mortality was rated per three replications (50 specimens) compared with a non-treated control colony.These results show that at the dilution rates used, the highest concentrations from both bark and leaf extracts achieved full mortality within one week of treatments. At $70 \%$ dilution rates, full mortality was achieved only 30 days after the evaluation period (data not provided). No significant mortality was found in either treatment at 30\% dilution rates, indicating that the minimum effective dosage should be explored at levels not below 50\%. In unsaponifiable matter (the sterol-containing fraction), we were able to detect various volatile compounds, which were most likely terpenoids (Figure 3 ). In addition, phytol and $n$ alcohols from 18 to 28 were detected, of which 24:0 was the most abundant. The labeled compound and its structure achieved a good match with the NIST MS library; however this was unverifiable due to the lack of a standard (due to it being a sesamin-related compound).

GC/MS analysis of the unsaponifiable matter of sesame oil, where sesamine is a well known constituent, verified detection of sesamine in Drymis winteri. $\beta$-Sitosterol was the only sterol detected in unsaponifiable matter (Figure 3).

\section{Conclusions}

Seven drimane-type sesquiterpenes, namely polygodial, drimenol, drimendiol, drimenin, isodrimininol, isodrimenin and proximadiol; the lignans sesamin, (the majority compound), cubebin, their epimers and eudesmin, and $\beta$-sitosterol were isolated from Drimys winteri (Winteraceae) collected from Chiloe Island, Chile. This is the first time that eudesmin has been isolated from this plant. Sesamin, $\beta$-sitosterol was the major products; and qualitative and quantitative differences were detected between products from Chiloe Island and Continental Drimys species. Some isolated compounds were tested against phytopathogenic fungi and assays were also carried out to determine the contact toxic action of leaf and stem bark extracts on phloematic pest insects.

\section{Acknowledgments}

The authors are indebted to Prof. Dr. Philippe Christen (Geneva University) for the acquisition of the NMR spectra.

\begin{tabular}{|l|l|l|l|l|}
\hline Drimys winterize & Place & Extract $\mathbf{( g r )}$ & Sesamin $(\mathbf{m g})$ & Yield \% \\
\hline Stem bark & Continental & 150 & 50 & 0.33 \\
\hline Stem bark & Chiloe Island & 96.1 & 3200 & 3.33 \\
\hline Leaves & Continental & 40.1 & 0.84 & 2.1 \\
\hline Leaves & Chiloe Island & 35 & 950 & 2.71 \\
\hline
\end{tabular}

Table 1: Quantification of eudesmin in Drimys winteri populations.

\begin{tabular}{|l|l|l|l|}
\hline Continental population & Polygodial (\%) & Sesquiterpenes (\%) & $\begin{array}{l}\text { Annual } \\
\text { precipitation } \\
\text { (mm) }\end{array}$ \\
\hline Central Chile (Oct.-Dec.) & 1.05 & $1-5$ & 370 \\
\hline Chiloé: Huillinco & -0.01 & 0.033 & 1900 \\
\hline Chiloé: Coihuin (Oct-Dec). & -0.75 & $0.002-0.21$ & 3400 \\
\hline
\end{tabular}

Table 2: Variability Sesquiterpenes in $D$. winteri from Continental and Island Populations.

\begin{tabular}{|c|c|c|c|c|}
\hline \multirow[t]{2}{*}{ Compound tested } & \multicolumn{4}{|c|}{ Phytopathogenic fungus } \\
\hline & $\begin{array}{l}\text { Botritys } \\
\text { cinerea }\end{array}$ & $\begin{array}{l}\text { Dothiorella } \\
\text { sp. }\end{array}$ & $\begin{array}{l}\text { Penicillium } \\
\text { sp. }\end{array}$ & $\begin{array}{l}\text { Cladosporium } \\
\text { cladosporoides }\end{array}$ \\
\hline $\begin{array}{l}\text { Polygodial } \\
\text { Sesamin } \\
\text { Drimenol } \\
\text { Eudesmin } \\
\text { Isodrimenin } \\
\text { Polygodial +drimenin } \\
\text { Polygodial +Isodrimeninol } \\
\\
\text { Iprodione1 (reference) } \\
\text { Myclobutanil2(reference) }\end{array}$ & $\begin{array}{l}67.5 \\
>600 \\
>600 \\
>200 \\
>600 \\
62.4 \\
62.5 \\
31.3 \\
15.6\end{array}$ & $\begin{array}{l}337.5 \\
>600 \\
>600 \\
>200 \\
585 \\
154 \\
215 \\
6.5 \\
18.4\end{array}$ & $\begin{array}{l}>600 \\
>600 \\
>600 \\
>200 \\
>600 \\
>600 \\
>600 \\
35.8 \\
54.2\end{array}$ & $\begin{array}{l}337.5 \\
>600 \\
>600 \\
>200 \\
\\
585 \\
225 \\
312.5 \\
12.7 \\
37.2\end{array}$ \\
\hline
\end{tabular}

Table 3: Antifungal activity of some compounds isolated from Drimys winteri. Data reported as MIC in $\mu \mathrm{g} / \mathrm{mL}$. 
Citation: Muñoz O, Gutierrez M, Gonzalez R, Hammann S, Vetter W (2015) Antifungal and Insecticidal properties of the Phytoconstituents of Drimys winteri (Winteraceae) growing in Chiloe Island (Chile). Nat Prod Chem Res 3: 182. doi:10.4172/2329-6836.1000182

Page 6 of 6

\section{References}

1. Jordan M, Peña R, Winteri JRD, Foster G (2005) In Muñoz O, Fajardo V, Flora de Chile: Biologia, Farmacologia y Quimica U. de Chile-Cyted 41-54.

2. Rodríguez R, Quezada M (1991) Nueva Combinación en Drimys J.R. et GForster (Winteraceae) de Chile. Gayana Bot 48: 111-114.

3. Concha DM, Vogel H, Yunes R, Razmilic I, Bresciani L, et al. (2007) Presence of polygodial and drimenol in Drimys population from Chile. Biochem Sys Ecol 35: 434-438

4. Marticorena C, Quezada M (1985) Catälogo de la Flora vascular de Chile. Gayana Bot 42: 13-114.

5. Muñoz O, Montes M, Wilkomirsky T (2001) Plantas medicinales de uso en Chile: Química y farmacología. Ed. Universitaria.

6. Rodriguez B, Zapata N, Medina P, Viñuela E (2005) Spectral Assignments and Reference Data. A complete $1 \mathrm{H}$ and 13C NMR data assignment for four Drimane sesquiterpenoids isolated from Drimys winterii. Magn Res Chem 43 : $82-84$

7. Monsalvez M, Zapata N, Vargas M, Bittner M, Hernandez V (2010) Antifungal effects of $n$-hexane extra and essentials oils of Drimys winteri bark against Take-All disease. Ind Crops Prod 31: 239-244.

8. Zapata N, Budia F, Viñuela E, Medina P (2009) Antifeedant and growth inhibitory effects of extracts and drimanes of Drimys winteri stem bark against Spodoptera littoralis (Lep., Noctuidae) Ind Crops Prod 30: 119-125.

9. Jansen BJM, Groot AD (2004) Occurrence, biological activity and synthesis of drimane sesquiterpenoids. Nat Prod Rep 21: 449-477.

10. Jansen BJM, Groot AD (1991) The synthesis of drimane sesquiterpenoids. Nat Prod Rep 8: 309.

11. Brown GD (1994) Drimendiol a sesquiterpene from Drimys winteri. Phytochem35: 975-977.

12. Aasen AJ, Nishida J, Enzell CD, Appel H (1977) The structure of $(11 \xi, 12 \xi)$ 11, 12-Di (7-drimen-11-oxy) 11, 12-epoxy 7-drimene. Acta Chem. Scand B31: $1555-1558$.

13. Fromm E, Santos E (1997) Winteraceas. In Reitz R, Reis A (Eds.). Florallustrada Catarinense I Parte Itajai, Santa Catarina, Brazil: 1-19.

14. Osorio LM, Cortes M, Armstrong V, Bailen M, Coloma AG (2008) Antifeedant activity of some Polygodial Derivatives. Z Naturforsch 63: 215-220.

15. Fujita K, Kubo I (2003) Synergism of poligodial and trans-cinnamic acid on inhibition of root elongation in Latucce seeding growth bioassays. J Chem Ecol 29: 2253-2262.

16. Munoz O, Christen P, Cretton S, Barrero AF, Laraf A, et al. (2011) Comparison of the Essential Oils of Leaves and Stem Bark from Two Different Populations of Drimys winteri a Chilean Herbal Medicine. Nat Prod Commun 6: 879-882.

17. Pothacharoen PP, Settakorn J, Poompimol W, Caterson B, Kongtawelert P (2012) Chondroprotective and anti-inflammatory effects of sesamin. Phytochem 80: $77-88$.

18. Jayasinghe L, Kumarihamy M, Jayarathna N, Udishani G, Bandara R, et al. (2003) Antifungal constituents of the stem bark of Bridelia retusa. Phytochem 62: 637-641.

19. Kuchkova K, Aricu N, Dragalin P, Vlad P (2004) Convenient synthesis of drimenol and its oxidation with selenium dioxide. Russ Chem Bull, Int Ed 53: 2862-2865.

20. Harrigan GG, Ahmad A, Baj N, Glass TE, Guaatilaka A, et al. (1993) Bioactive and other sesquiterpenoids from Porella cordeana. J Nat Prod 56: 921-925.

21. Akita $H$, Nozawa M, Mitsuda A, Ohsawa $H(2000)$ A convenient synthesis of $(+)$ - albicanol based on enzymatic function: total syntheses of $(+)$-albicany acetate, (-) - albicanyl 3, 4-dihydroxycinnamate, (-) -drimenol, (-) -drimenin and (-) -ambrox. Tetrahedron Asymmetry 11: 1375-1388

22. Appel HH, Conolly JD, Overton KH, Bond R (1960) Sesquiterpenoids. Part I The constitution and stereochemistry of drimenin, Isotrimenin and confertifolin. J Chem Soc 82: 4685-4692.

23. 23. Maurs M, Azerad R, Corte M, Aranda G, Bertranne M, et al.(1999) Microbial hydroxylation of natural drimenic lactones. Phytochem 52: 291-296.

24. Zhang XY, Li1 B, Zhou M, Yuan X, Zhang G (2006) Chemical Constituents of
Phacellaria compressa Benth. J Integr Plant Biol 48: 236-240.

25. Frederick KE, Dwight W, Thomas C, Vernor B, Wnkert E (1982) Structure Analysis of Proximadiol (criptomeridiol) by ${ }^{13} \mathrm{NMR}$ Spectroscopy. Phytochem 21: $937-938$.

26. Sierra JR, Lopez J, Cortes M (1986) (-) -3ß-acetoxy drimenin from the leaves of Drimys winteri. Phytochem 25: 253-254.

27. Meselhy MR (2003) Constituents from Moghat, the Roots of Glossostemon bruguieri (Desf.). Molecules 8: 614-621.

28. Pascol ID, Nascimento I, Lopes L (2006) Configurational analysis of cubebins and bicubebin from Aristolochia lagesiana and Aristolochia pubescens. Phytochem 67: 735-742.

29. Morais S, Teixeira A, Torres Z, Nunomura S, Kanashiro EY, et al. (2009) Biological Activities of Lignoids from Amazon Myristicaceae Species: Virola michelii, V. mollissima, V. pavonis and Iryanthera juruensis. J Braz Chem Soc 20: $1110-1118$.

30. Tuleda LR, Barchiesi F, Bille J, Chryssanthou E, Estrella MC, et al. (2002) Method for the determination of minimum inhibitory concentration (MIC) by broth dilution of fermentative yeast. ESCMID European Committee for Antimicrobial Susceptibility Testing (EUCAST). Discussion Document E. Dis 7.1: 1-8.

31. Favre B, Hofbauer B, Hildering K, Ryder NS (2003) Comparison of in Vitro activities of 17 antifungal drugs against a panel of 20 dermatophytes by using a microdilution assay. J Clin Microbiol 41: 4817-4919.

32. Gutierrez M, Theoduloz C, Rodriguez J, Lolas M. Schmeda-Hirschmann (2005) Bioactive metabolites from the fungus Nectria galligena, the main apple canker agent in Chile. J Agric Food Chem 53: 7701-7708.

33. Hueso-Rodríguez J, Rodríguez B (1989) A new and efficient route to optically active drimanes. Synthesis of $(+)$-winterin, $(+)$-confertifolin, $(+)$-isodrimenin, and $(+)$-bicyclofarnesol. Tetrahedron. 45: 1567-1576.

34. Lee Ch, Chim Yen G (2006) Antioxidant Activity and Bioactive Compounds of Tea Seed (Camellia oleifera Abel.) Oil. J Agric Food Chem 54: 779-784.

35. Himejima M, Kubo I (1992) Antimicrobial agents from Licaria puchuri-major and their synergistic effect with polygodial. J Nat Prod 55: 620-625.

36. Kang R, Helms R, Stout M, Jaber H, Chen Z, et al. (1992) Antimicrobial activity of the volatile constituents of Perilla frutescens and its synergistic effect with polygodial. J Agric Food Chem 40: 2328-2330.

37. Saleem M, Kim HJ, Ali MS, Lee YS (2005) An update on bioactive plant lignans. Nat Prod Rep 22: 696-716.

38. Harmatha J, Nawrot J (2002) Insect feeding deterrent activity of lignans and related phenylpropanoids with a methylenedioxyphenyl (piperonyl) structure moiety. Entomol Exp Appl 104: 51-60.

39. Muñoz O (2015). Personal communication.

40. Verdeguer M, Rellán DG, Boira H, Pérez E, Gandolfo S, et al. (2011) Herbicida Activity of Peumus boldus and Drimys winteri Essential Oils from Chile. Molecules 16: 403-411.

41. Pacheco A, Nunes R, Alcantara A, Veloso P (2013) Theoretical study of structural $\alpha$-and $\beta$-cubebin isolated from Aristolochia esperanzae Kuntze. Planta Med 79: 5 .

42. Bustos J, Carvalho CT. de Souza, Pedrazzi G, Sarti HP (2001) Anti-inflammatory activity of cubebin, a lignan from the leaves of Zanthoxyllum naranjillo Griseb. J Ethnopharmacol 75: 279-282. 